Aleksandra Milovanović

Univerzitet umetnosti u Beogradu

Fakultet dramskih umetnosti
UDC: $316.774: 37$

DOI: 10.18485/dh.2015.2.ch10

\title{
MEDIJSKA PISMENOST: FUNKCIONALNA (NE)POVEZANOST EKRANSKE KULTURE I ŠKOLSKIH KURIKULUMA
}

\begin{abstract}
Sažetak
Deca i omladina su danas okruženi medijima i ekranima, jer kuda god da se kreću oni su svuda oko njih: kod kuće (televizor, kompjuter, konzola za video-igre, itd.), u školi, u automobilu, na ulici, pored autoputa, u javnom prevozu (autobusu, vozu), u tržnim centrima, čekaonicama, sportskim arenama itd., a u izuzetno retkim situacijama kada u njihovoj okolini nema ekrana, uvek mogu da se okrenu ekranu na svom telefonu ili tabletu koji je neprestano uz njih. Prema istraživanju evropskih eksperata za obrazovanje, čiji su rezultati izloženi u studiji Za evropsku filmsku obrazovnu politiku (For a European Film Education Policy, 2014), deca u osnovnoj školi provode godišnje 900 sati u školskoj klupi, a čak 1.200 sati pred ekranom (bilo koje vrste), a da pritom ne znaju na koji način nastaju i šta znače slike koje im se na tim ekranima nude. Cilj ovog rada je da prouči ulogu, funkciju i značaj ekrana u savremenoj kulturi i analizira da li u Srbiji u sistemu formalnog školskog obrazovanja (predškolskog, osnovnoškolskog, srednjoškolskog itd.) postoji veza između kurikuluma i medijske pismenosti.
\end{abstract}

Ključne reči: mediji, ekrani, obrazovanje, medijska pismenost

Promena uloge, funkcije i značaja ekrana u savremenoj kulturi usko je povezana sa izazovima i efektima razvoja medija i koegzistencijom starih i novih (digitalnih) medija. U poslednje tri decenije došlo je do značajne proliferacije veličine ekrana (question of scale), mobilnosti ekrana, umnožavanja ekrana na kojima recipijenti istovremeno obavljaju više radnji na više ekrana (multi-tasking spectator), uslovljavajući na taj način nastanak efekta drugog ekrana, itd. Najvažnija pitanja koja se postavljaju i istražuju u savremenoj ekranskoj kulturi, a odnose se na oblast filma, jesu: veličina i mobilnost ekrana na kojima se filmovi mogu gledati, promena mesta na kojem se filmovi gledaju (relokacija i migracija filmova), 
praćenje više ekrana u toku filma, i slično. To znači da „na usložnjavanje percepcije i recepcije filma u savremenoj kulturi i medijima značajno utiču promena veličine ekrana, od minijaturnih do kolosalnih (from miniature to colossal), mobilnost ekrana (from static to movable screens), relokacija ekrana (from film theaters to urban screens) i umnožavanje ekrana" (Milovanović 2014, 146).

U izveštaju Ksevijera Lardua (Xavier Lardoux) Za evropsku filmsku obrazovnu politiku namenjenom Evropskoj komisiji (European Commission) u Briselu istražuju se i opisuju načini uz pomoć kojih može da se ubrza inicijativa za razvoj audio-vizuelnog obrazovanja i medijske pismenosti, sa naglaskom na filmu, u zemljama Evropske unije. Kao uzroci hitnosti ove inicijative u izveštaju se među najvažnijima najpre navode proliferacija i sveprisutnost ekrana (različitih vrsta) u savremenoj kulturi, a zatim i dominacija američkih sadržaja na njima. Zbog toga se naglašava važnost filmskog i medijskog obrazovanja dece i omladine (starosti 3-18 godina), ali i njihovog uvezivanja sa evropskom filmskom tradicijom i savremenim trendovima. Formiranje novih školskih kurikuluma za predškolsko, osnovno i srednjoškolsko obrazovanje u kojima postoje obavezni programi za audio-vizuelno obrazovanje i pismenost ima za cilj razvoj buduće filmske publike koja će biti senzibilisana za evropski film, kao i za raznolikost kultura i identiteta u 22 evropske zemlje.

U studiji Za evropsku filmsku obrazovnu politiku naveden je primer da u Francuskoj deca u osnovnoj školi prosečno provode 900 sati godišnje u školskoj klupi, a čak 1.200 pred ekranom (bilo koje vrste). Takođe, navode se procene Eurodate, svetske televizijske studije (Eurodata TV Worldwide study, 2013) da tinejdžeri (uzrasta 13-18 godina) umesto bioskopskih i televizijskih ekrana koriste kompjuterske ekrane i ekrane mobilnih elefona i tableta na kojim $80 \%$ vremena provode na internet stranicama sa video-sadržajem (video-sharing sites) zabog čega ih nazivaju i Jutjub generacijom (The YouTube generation). Uz ove izveštaje Evropska audiovizuelna opservatorija (European Audiovisual Observatory, 2013) objavila je podatke koji se odnose na sadržaje koji su deci i omladini dostupni na ekranima koji ih okružuju. U ovom trenutku u Evropskoj uniji dostupno je 309 dečjih televizijskih stanica, od čega je njih 157, odnosno 50,8\%, u vlasništvu tri američke medijske kompanije: Tajm Vorner (Time Warner), 
Volt Dizni (The Walt Disney Company) i Vajakom (Viacom), koje utiču na standardizaciju i uniformnost programa za decu na svetskom nivou i umanjuju prostor za raznolikost evropskih programa za ovu publiku. Takođe, statistika Evropske komsije ${ }^{1}$ iz 2014. godine ukazuje da su tinejdžeri (starosti 16-19 godina) 2006. godine u bioskopima u proseku pogledali 4 film, a da je 11,2\% gledalao više od 12 filmova, 15,5\% između 7 i 12 filmova, 25,5\% između 4 i 6 filmova, 32,3\% između 1 i 3 filma, a da čak 15,5\% ispitanih tinejdžera te godne nije uopšte išlo u bioskop. Kada se govori o bioskopskim ekranima i filmovima, treba imati u vidu da su na primer 1993. godine deca i omladina (uzrasta do 25 godina) činili $44 \%$ bioskopske publike, a 2012. godine samo 31,5\%, što nam ukazuje na trend opadanja interesovanja za gledanje filmova u bioskopima u poslednjih 20 godina.

Francuski edukativni programi Škola u bioskopu (Ecole et cinéma, 1994), Škola filma (Collège au cinéma, 1989) i Filmski početnici i učenici (Lycéens et apprentis au cinéma, 1998) nude učenicima, kao i njihovim profesorima, priliku da otkriju filmsku umetnost kroz projekcije koje se organizuju u bioskopima posebno za njih. Cilj je da se mladima približi film kao umetnost, da se stimuliše njihovo interesovanje za raznolikost filmske umetnosti i da se uspostavi odnos između mlađe generacije i bioskopa. U školskoj 2011/12. godini, u Francuskoj je ova tri programa pohađalo 1.410.000 učenika, što predstavlja najznačajniji doprinos umetničkoj, kulturnoj i filmskoj edukaciji u vreme nastave. Ovi učenici jednom mesečno imaju obavezu da za vreme časova sa svojim profesorima posete bioskop. $\mathrm{U}$ tekstu Hipnotizam bioskopa, mali traktat o prelasku bioskopa u škole $i$ druga mesta (L'Hypothèse cinéma, petit traité de transmission du cinéma à l'école et ailleurs, 2002) Alan Bergela (Alain Bergala) ističe da glavna platforma za filmsko obrazovanje treba da bude škola, jer to omogućava da se dopre do velikog broja dece bez obzira na ekonomske, socijalne i kulturne barijere. Marta Nusbaum (Martha Nussbaum) u knjizi Ne za profit, zašto su demokratskom društvu potrebne humanističke nauke (Not for Profit, Why Democracy Needs the Humanities, 2010) navodi da je za ideju Evropske unije, njenog zajedništva i raznolikosti posebno važna kul-

1 Za širi uvid u ove podatke pogledati Eurostst: Frequency of going to cinema, live performances, cultural sites or attending live sport events by sex and age (31.01.2014) http://appsso.eurostat.ec.europa.eu/nui/show.do?dataset=yth_cult_010\&lang=en 
tura, a da je film najjednostavniji način uticaja na mlade generacije koje će ovu ideju održati i u budućnosti. Studija Za evropsku filmsku obrazovnu politiku predlaže sledeće modele za uspešne programe filmskog obrazovanja i medijske pismenosti: a) projekcije tokom školskih časova, često u bioskopu, omogućavajući tako učenicima da gledaju klasike i savremene filmove koje će kasnije koristiti na času, naročito u učenju stranih jezika; b) praktične radionice na kojima mladi stvaraju filmove, od početne ideje do finalne verzije; c) filmske festivale i takmičenja posebno namenjene mladima; d) kurseve i treninge osmišljene za predavače (nastavnike, zaposlene u javnom sektoru zadužene za kulturu, omladinske organizacije itd.); e) upotrebu novih medija - tematskih veb-sajtova, onlajn video-platformi i blogova - koji su mladima bliski izvori za sve vrste obrazovanja, kao i filmskog; f) povezivanje dobrih programa i praksi od lokalnog, preko nacionalnog, do transnacionalnog i evropskog nivoa.

Britanski filmski institut (The British Film Institute) 2011. godine započeo je istraživanje koje je objavljeno 2013. godine u studiji Medijska (ekranska) pismenost, filmsko obrazovanje u Evropi (Screening Literacy, Film Education in Europe), u kojoj se u opštim crtama opisuju osnovni modeli postojećih programa medijske pismenosti. Na osnovu mesta i vremena u kojem se odvijaju, oni su podeljeni na: programe u školi za vreme časova, programe u školi van nastave i programe za školsku decu van nastave. $U$ ovoj studiji predlaže se i definicija medijske pismenosti sa akcentom na filmskom obrazovanju: „Razumevanje filma, kao i sposobnost da budemo svesni i radoznali u izboru filmova; kompetentnost da se kritički gledaju filmovi i analizira njihov sadržaj, ali i razumevanje kinematografskih i tehničkih procesa pomoću kojih su oni nastali; sposobnost upotrebe filmskog jezika i tehničkih resursa u kreativnoj proizvodnji pokretnih slika." (Reid, 2013, 8). Tokom analize mnogih pitanja odnosa medijske edukacije i pismenosti, kao najvažnije izdvaja se pitanje mesta - gde se ta edukacija odvija. Na osnovu tog pitanja edukacija je podeljena na obavezni deo školskog kurikuluma, izborne aktivnosti u školi pre ili posle časova i fakultativne programe posle škole. Takođe se navodi da je školski kurikulum najefikasniji način filmskog opismenjavanja mladih. U školama se film koristi kao pomoćno sredstvo u ostalim školskim predmetima (npr. dokumentarne emisije o fenomenima iz fizike i hemije, serije o 
istorijskim periodima, biografije poznatih naučnika itd.), a ova studija pokazuje potrebu da se filmska umetnost (i mediji uopšte) proučava u okviru posebnog predmeta. Drugi model, koji se za sada u Evropskoj uniji sve češće primenjuje u programima viših razreda osnovne škole i u srednjoj školi, podrazumeva da filmsko obrazovanje bude izborni predmet. Najmanje je zastupljen „model u kom je filmsko obrazovanje izdvojeni predmet u samom kurikulumu, i on se pojavio samo u jednoj zemlji u osnovnoj školi (primary level), u dve u višim razredima osnovne škole (middle level), i u četiri zemlje u srednjoj školi (high school level)“ (Reid 2013, 10).

U knjizi Publike (Audiences, 2012) Ijan Kristi (Ian Christie) navodi da „niko ne može poreći činjenicu da danas postoji više načina za gledanje filmova nego ikada ranije" (Chrstie 2012, 19). U savremenoj kulturi i medijima filmovi migriraju kroz čitav spektar različitih veličina ekrana koji se kreću od kolosalnih ekrana u zatvorenim prostorima (IMAX bioskopi, muzeji, koncertne hale, itd.), megaekrana na otvorenom (bioskopi na otvorenom, bilbordi, izlozi, video-bimovi itd.), preko niza ekrana srednjih veličina (različite vrste televizora, kućnih bioskopa, kompjuterskih ekrana, konzola za video-igre, portabl DVD uređaja itd.), do minijaturnih koji su statični (u avionu, autobusu, automobilu, tokom medicinskih intervencija itd.) i mikroekrana koje nosimo sa sobom dok smo u pokretu (iPhone, iPod Touch, smartphone, tablet, kindle, notebook itd.). Sve ove veličine ekrana utiču da, na primer, gledanje filmova, koje je nekada bilo lokalizovano u bioskopu ili dnevnoj sobi, migrira, odnosno relocira se na mesta gde se recipijenti i ekrani kreću. Tako Kristi u tekstu Šta zaista znamo o filmskim publikama? (What Do We Really Know About Film Audiences?, 2012) objašnjava da danas više ne možemo govoriti o filmskoj publici u jednini, već da zbog toga što različiti recipijenti imaju različite preferencije na kojim ekranima žele, i mogu, da gledaju filmove, kao i zbog toga što različiti režimi percepcije i recepcije filma prate izbor ekrana, potrebno je da koristimo množinu - publike (audiences). Lev Manovič (Lev Manovich) u tekstu Ka arheologiji kompjuterskog ekrana (Towards an Archaeology of the Computer Screen, 1998) iznosi tvrdnju da je društvo u kojem živimo nedvosmisleno „društvo ekrana (society of a screen)“ (Manovich 1998, 27). Kao ključna pitanja ekranskog društva Manovič navodi istorijske faze njegovog razvoja, kao i na koje načine proliferacija ekrana od minijaturnih 
do kolosalnih i od statičnih do pokretnih „u isto vreme i nastavlja i osporava istoriju ekrana" (Manovich 1998, 27).

Sve promene u savremenoj kuturi i medijima razvijaju se velikom brzinom, a njihovi efekti i uticaji još se ispituju, tako da je u ovom trenutku moguće samo uočiti i kategorisati ih, dok na njihove dugoročne efekte treba sačekati. Razumevanje važnosti medijske pismenosti dece i omladine najbolje se može razumeti na primeru filmske umetnosti, odnosno umnožavanju ekrana na kojima danas gledamo filmove, njihove dostupnosti, migracije i relokacije, a na osnovu promena u načinu gledanja filmova koje zbog toga nastaju može se istražiti uloga ekrana u savremenoj kulturi, i to kroz pitanja: 1) veličine i mobilnosti ekrana na kojima se filmovi mogu gledati; 2) promene mesta na kojem se filmovi gledaju; 3) novonastalih promena u procesima percepcije i recepcije filmske publike. Proteklih decenija veličina ekrana na kojima gledamo filmove značajno se povećala, ali da li su zbog toga, usled popularnog mišljenja da je „veće i bolje“, i naša percepcija i recepcija filma dobile na kvalitetu²? Ijan Simons (Ian Simons) ističe važnost izbora veličine ekrana u odnosu na vizuelni sadržaj koji ćemo na tom ekranu gledati jer se na mikroekranima grandioznost scena u, na primer, istorijskom spektaklu ili ratnom filmu ne može doživeti kao na makroekranima na kojima se vidi svaki njihov detalj. Takođe, recipijenti danas, smatra Nana Verhof (Nanna Verhoeff), imaju mnogo ličniji odnos prema ekranima jer uređaje sa mikroekranima mogu da nose sa sobom, drže u ruci, dodiruju ih (touch screen), itd. Da bi opisala sve ove novonastale promene, ona uvodi pojam taktilne recepcije (tactile reception) koja proizvodi efekat „umrljanih ekrana (a dirty window)“ (Verhoeff 2012, 82-89). Tokom prikazivanja filma u bioskopu ili na televiziji, ističe Verhof, recipijenti nikada ne dodiriju ekran (ili to nije uobičajeno), dok na mobilnom telefonu i tabletu zbog interaktivnosti njihovih ekrana recipijenti dodirom pokreću film, preskaču njegove delove, ubrzavaju ga, zaustavljaju, prate nekoliko ekrana na jednom, povećavaju sliku (resize) kako bi što bolje videli određeni detalj u njoj, itd.

2 Za detaljniji rezime pogledati tekst „Percepcija filmova, efekti odnosa fizičke veličine ekrana i vrste kadra koja se na njemu prikazuje" (Perception While Watching Movies, Effects of Physical Screen Size and Scene Type) Trošijanka, Misa i Hinda (T. Troscianko, T. S. Meese, S. Hinde) objavljen 2012. godine u časopisu i-Perception 3, no.7, str. 414-425. 
Istorijski posmatrano, veličina ekrana, od njihovog nastanka do danas, permanentno se menjala, navodi Ani van den Over (Annie van den Oever) u svom tekstu Estetika i vizuelni režimi filma i televizije (The Aesthetics and Viewing Regimes of Cinema and Television, 2012), na osnovu analize dijalektičkog uticaja bioskopskog i televizijskog ekrana u pogledu njihove veličine. Ubrzani razvoj televizije uslovio je da mnogi gledaoci umesto odlaska u bioskop ostanu kod kuće i gledaju filmove. Međutim, veličina ekrana prvih televizora (RCA 630 i RCA 621) bila je 7-10 inča, tako da je filmska industrija na ovaj izazov odgovorila snimanjem filmova za veće i kolosalnije bioskopske ekrane (Widescreen, CinemaScope, VistaVision itd.). Filmovi pravljeni za ove široke ekrane imali su cilj da „ekran televizora u dnevnoj sobi izgleda sićušno (miniscule), podsećajući publiku da su za sinemaskop filmove potrebni mamutski ekrani (mammoth screens)" (Oever 2012, 121). Danas su se televizijski ekrani povećali na veličinu kućnog bioskopa (home theater sistems), čiji je kvalitet slike i zvuka isti kao u bioskopu (ako ne i bolji3). Odgovor filmske industrije na ovaj izazov su 3D i IMAX bioskopi u kojima se nalaze platna veličine do 200 metara kvadratnih i „čije dimenzije očigledno imaju izuzetan efekat na gledaoce“ (Over 2012, 121). Ubrzano umnožavanje veličine ekrana u savremenoj kulturi i medijima uticalo je na dalju migraciju i relokaciju filmova, od bioskopa i televizora do mobilnih telefona i tableta. Mobilni filmovi (mobile films, portable films), mikrofilmovi (micromovie, cellphone movies) i džepni filmovi (pocket films) slični su džepnim knjigama (pocket books), navodi ljan Simons u tekstu Između mobilnog telefona i Jutjuba, filmovi u pokretu (Between Iphone and YouTube, movies on the move, 2011), pozivajući se na sličnost u njihovoj „veličini (portability), mobilnosti (mobility) i jednostavnosti (easy digestibility)“ (Simons 2011, 98). Rodžer Odin (Roger Odin) u tekstu Gledalac, film i mobilni telefon (Spectator, Film and the Mobile Phone, 2012) primećuje da omogućavajući dostupnost (accessibility) filmova za gledanje u bilo koje vreme i na bilo kom mestu mobilni telefoni i tableti „otvaraju novi prostor za distribuciju i recepciju filmova kakav ni na jedan drugi način ne bi postojao" (Odin 2012, 159).

3 U skladu sa trendom ubrzanog rasta veličine ekrana, bitno je naglasiti da su dimenzije TV ekrana dugo smatrane relativno nevažnim, kao i da su veliki televizori, kao deo kućnog nameštaja, smatrani nepraktičnim. 
Pitanje mesta gde gledamo filmove povezano je sa mobilnošću ekrana koji više nisu fiksni (bioskopsko platno, televizijski prijemnik itd.), već se kreću sa gledaocem (tablet, mobilni telefon), ili mogu biti kombinacija fiksnog i mobilnog ekrana (gledanje filma u avionu, kolima, kafiću, autobus itd.). Publika danas više ne ide na određeno mesto na kom može da pogleda film, već film dolazi tamo gde je publika. U današnjoj medijskoj ekologiji (media ecology ${ }^{4}$ ), odnosno medijskom okruženju, „ekrani su postali sveprisutni“ (Simons 2012, 101) jer gde god da se krećemo oni su svuda oko nas: kod kuće, na poslu, u školi, u javnom prevozu (autobusu, vozu), u privatnom automobilu, na ulici, pored autoputa, u tržnim centrima, čekaonicama, barovima, aerodromima, sportskim arenama i slično, a u izuzetno retkim situacijama kada u našoj okolini nema ekrana, uvek možemo da se okrenemo ekranu na svom telefonu koji je uvek uz nas. Do pre tri decenije gledanje filmova bilo je lokalizovano i standardizovano, film se mogao gledati u opuštenoj kućnoj atmosferi, u specijalizovanim bioskopima (drajv-inu, filmskom klubu, kinoteci, muzeju, itd.) i bioskopskoj dvorani (pojedinačnoj ili sinepleksu). Sa umnožavanjem i mobilnošću ekrana „pokretne slike su napustile poznata okruženja (biotopes), bioskopsku salu i dnevnu sobu“ (Simons 2009, 7), što je za posledicu imalo to „da gledaoci više nisu išli tamo gde je film, već je on počeo da se kreće sa gledaocima" (Oever 2012, 117). Bioskop i televizija, nekada ekskluzivna mesta za gledanje filmova, „danas su samo jedna od mnogih“ (Simons 2011, 102). Međutim, iako se savremena kultura i mediji danas sve više okreću ka individualnom gledanju filmova i mobilnim ekranima, publika i dalje odlazi u bioskop radi posebnosti kolektivnog (plemenskog) doživljaja gledanja filma 5 .

Nekada je gledanje filmova uglavnom bilo vezano za „odlazak u bioskop (going out to the cinema)" (Oever 2012, 117), dok su danas gledaoci

$4 \quad$ Medijska ekologija je teorijski koncept koji je sredinom šezdesetih godina prošlog veka predstavio Maršal Mekluan (Marshall McLuhan), dok je sam termin skovao Nil Postam (Neil Postman) koji smatra da je „Medijska ekologija način na koji mediji utiču na našu percepciju, razumevanje, osećanja i vrednosti. Reč ekologija u ovom terminu upućuje da je to studija o medijskom okruženju (environments): njihovoj strukturi, osobinama i uticaju na recipijente" (Postman 1979).

5 Za detaljniji rezime pogledati tekst Torbena Grodala (Torben Grodal) „Osluškivanje našeg plemenskog nasleđa, Gospodar prstenova i evolucija“" (Tapping into Our Tribal Heritage, The Lord of the Ringsa and Brain Evolution) objavljen 2012. godine u knjizi Publike (Audiences), str. 128-142. 
oslobođeni prostornih i temporalnih bioskopskih ograničenja (vremena i mesta filmske projekcije), a zahvaljujući diversifikaciji mesta i načina za gledanje filmova slobodni su da odluče gde, kada, kako i koje filmove će gledati $^{6}$. Na savremeno usložnjavanje percepcije i recepcije filma utiču umnožavanje ekrana, mobilnost ekrana, veličina ekrana, ali i povećana dostupnost filmova na: kablovskim, satelitskim i internet kanalima7 (pretplata ili naručivanje pojedinačnog programa); specijalizovanim kanalima (narrowcasting); sistemima za odloženo gledanje omiljenih programa i izbegavanje reklama (video-rikorder, TiVo, Replay); kroz internet redistribuciju, oficijalnu (online, streaming, download, TV/dot-com, pay-per-view, Netflix, Cinemax, SBB) i neoficijalnu (p2p, torrent); na DVD-ju i Blu-ray disku (kupljenom ili iznajmljenom), itd. Filmove možemo zaustaviti, pauzirati, vratiti unazad, premotati unapred, možemo promeniti kanal ili raditi nekoliko radnji istovremeno na više ekrana (multi-tasking spectator). Navedene promene u režimima percepcije i recepcije filma dodatno su usložnjene efektom „drugog ekrana“, koji nastaje kada gledalac u isto vreme na jednom ekranu prati film (u bioskopu ili na televiziji) a na drugom ekranu (mobilnom telefonu, tabletu ${ }^{8}$ ) šalje SMS-ove i tvitove, proverava elektronsku poštu, itd.

U tekstu Obrazovna i kulturna politika, dramske umetnosti u školama (2010) Vesna Đukić postavlja dva pitanja, od kojih je prvo u vezi sa proučavanjem odnosa između obrazovne i kulturne politike u Srbiji na različitim nivoima obrazovanja. Drugo pitanje u njenom istraživanju tiče se uloge audio-vizuelnih umetnosti u obrazovnom sistemu, kao i postojećih i mogućih oblika „zastupljenosti ove umetničke discipline u nastavnim pro-

Ovaj proces „odomaćivanja filma (the domestication of film)“ (Jullier/Leveratto 2012, 153) oslobodio je gledaoce komercijalnog filmskog repertoara u bioskopskoj distribuciji, koja se u najvećoj meri oslanjala na trenutnu punudu aktuelnih filmova.

7 Sve ove inovacije u distribuciji filmova i televizijskog programa (u celini ili pojedinačno) uticale su na promenu modela recepcije i svakodnevne navike gledaoca. Na primer, linearni i monolitni model emitovanja televizijskog programa koji Rejmond Vilijams (Raymond Williams) u svojoj knjizi Televizija: tehnološka i kulturalna forma (Television: Technology and Cultural Form, 1974) opisuje kao koncept toka (flow) zamenio je fragmentarni model koji je nastao kao posledica umnožavanja televizijskih kanala, pojave interneta, itd. Korišćenje drugog ekrana može biti putpuno nezavisno od prvog, ali može biti i u njegovoj službi. Na primer, u bioskopu ili kod kuće dok gledamo film možemo da tvitujemo o njemu, postavljamo komentare na internet, itd. 
gramima škola u Srbiji“ (Đukić 2010, 195). U sistemu formalnog osnovnog i srednjeg obrazovanja u Srbiji postoji neravnomerna zastupljenost umetničkih disciplina „zbog koje su likovna i muzička kultura zastupljene u nastavnom programu kao nastavni predmeti, dok su dramske umetnosti zastupljene samo neformalnim i informalnim sistemom vannastavnih aktivnosti“ (Đukić 2010, 196). Svrha savremenog programa obrazovanja u Srbiji, navodi Đukićeva, definisana je u nastavnom programu za osmi razred osnovnog vaspitanja i obrazovanja kao „kvalitetno obrazovanje i vaspitanje, koje omogućava sticanje jezičke, matematičke, naučne, umetničke, kulturne, zdravstvene, ekološke i informatičke pismenosti, neophodne za život u savremenom i složenom društvu“ (Đukić 2010, 203). Pored navedenih različitih oblika pismenosti neophodnih za život, ovaj nastavni program uključuje i „umetničku i kulturnu pismenost“ (Isto).

Postojeći školski kurikulumi u osnovnim i srednjim školama poznaju tri različita oblika učenja, i to: o umetnosti, pomoću umetnosti i za umetnost. „U sistemu učenja o umetnosti, ona se proučava u okviru nastavnih predmeta kao što su jezik (srpski i maternji), muzička kultura, likovna kultura i drugi (domaćinstvo, informatika); u sistemu učenja pomoću umetnosti - ona se koristi kao metod učenja i način produbljivanja razumevanja različitih predmeta obuhvaćenih nastavnim programom; u učenju za umetnost koji je razvijen u osnovnim i srednjim umetničkim školama i fakultetima - učenici i studenti obučavaju se za umetničko stvaralaštvo." (Đukić 2010, 200). Umetnička, kulturna, medijska i filmska pismenost dece i omladine značajan je faktor formiranja kulturnih potreba, navika i interesovanja pomoću kojih oni razvijaju svoju ličnost tako da „aktivno deluje, proizvodi, stvara nove materijalne i duhovne vrednosti, uživa u postojećim, komunicira" (Dragićević-Šešić/Stojković 2003, 16). S obzirom da ovi faktori zavise od obrazovanja, kao i od drugih kulturnih, socijalnih i materijalnih faktora, „potrebno je da postoji funkcionalna povezanost obrazovne i kulturne politike“ (Đukić 2010, 203).

U Srbiji su organizacije Film kultura i Slobodna zona Junior posvećene edukaciji i opismenjavanju dece i omladine u oblasti audio-vizuelne kulture i umetnosti. Njihov cilj je obrazovanje mladih, koji kroz njihove programe saznaju i uče kako nastaju slike na ekranima koje gledaju i šta one znače. Takođe, još jedan važan cilj ovih programa je formiranje i 
oblikovanje kritičkog mišljenja kod mladih o ovim slikama. Film kulturu je 2013. godine osnovalo šest mladih filmskih umetnika iz različitih sfera kinematografije (režije, produkcije, dramaturgije, montaže, kamere) u želji da deci i omladini prenesu deo svog iskustva i znanja iz oblasti audio-vizuelne kulture, a pre svega kinematografije.

Film kultura sadrži sledeće segmente: Dan domaćeg filma, Izoštravanje, Najkraći dan i dva edukativna programa za decu i omladinu: Šta gledaš, Mali film. Dan domaćeg filma je program posvećen promociji domaćeg filmskog stvaralaštva i održava se jednom mesečno u 11 gradova Srbije. Kroz ovaj program predstavljeno je 14 filmskih ostvarenja domaćih autora, a nakon svake projekcije publika je bila u prilici da razgovara sa autorima filmova. Izoštravanje predstavlja projekat za profesionalni razvoj i dalju edukaciju filmskih radnika i studenata umetničih fakulteta, kao i drugih stručnjaka iz oblasti audio-vizuelne kulture i umetnosti, a održava se 21. decembra, na najkraći dan u godini, koji je zbog svoje simbolike proglašen za Svetski dan kratkometražnog filma, te se kao takav obeležava širom Evrope i sveta u cilju afirmacije ove filmske forme. Osim u Beogradu, Film kultura organizuje ovu manifestaciju u još 11 gradova širom Srbije.

Kroz svoj edukativni program Šta gledam, namenjen deci i omladini 5-19 godina, Film kultura nastoji da: 1) razvije kreativno i kritičko mišljenje u oblasti audio-vizuelne kulture i umetnosti; 2) upozna ih sa svetskim i nacionalnim filmski nasleđem; 3) unapredi vizuelno opažanje i stvaralački potencijal kod mladih; 4) održi kulturu posećivanja bioskopskih predstava; 5) povezuje filmsku umetnost sa ostalim umetnostima i naukama. Ovaj program se odvija kroz „teorijska predavanja, projekcije audio-vizuelnih sadržaja (film, TV, video-art), sa posebnim akcentom na stimulaciju kritičkog razmišljanja, praktične vežbe prilagođene uzrastu i profilu učesnika“. Edukativni program organizacije Film kultura podeljen je prema uzrastu na decu u predškolskim ustanovama (5-6 godina), učenike osnovnih škola (7-15 godina) i učenike srednjih škola (15-19 godina).

Drugi edukativni program za decu i mlade Film kulture je Mali film i namenjen je uzrastu 5-14 godina, a za cilj ima popularizaciju filmske umetnosti kod najmlađe publike. Ideja Malog filma je da kod dece probudi kreativnost i radoznalost, a pre svega da stvori preduslov za kritički odnos prema medijskim sadržajima koji im se nude na ekranima koji ih 
okružuju. Program sadrži praktične vežbe kroz koje deca samostalno dolaze do zaključaka i slobodno formiraju mišljenja, što je najbolji put ka tome da ona usvoje i naknadno primene stečeno znanje. Mali film sadrži i namenski osmišljene igre koje mlade podstiču na aktivno učešće u stvaranju audio-vizuelnih sadržaja, sa kojima se inače susreću samo iz položaja gledalaca ispred ekrana. Kroz interaktivne radionice, koje rezultiraju kratkim animiranim ili igranim filmovima čiji su autori upravo učesnici, ovaj program deci otvara „svet pokretnih slika“. Prolazeći kroz pojednostavljene procese kojima se bave i filmski radnici, deca su u stanju da bolje razumeju filmsku umetnost. U okviru Najkraćeg dana 2014. godine Film kultura je organizovala radionicu za srednjoškolce Kratka škola kratkog filma u 11 gradova u Srbiji (Beograd, Novi Sad, Šabac, Arilje, Vrnjačka Banja, Leskovac, Smederevo, Negotin, Niš, Pančevo, Gornji Milanovac), a kroz nju je prošlo svega oko 80 dece. U 2014. godini kroz ovaj program prošlo je preko 800 učesnika uzrasta 5-14 godina. U 2015. godini Mali film je održan u tri grada u Vojvodini (Subotica, Zrenjanin, Pančevo), na tri beogradske opštine (Sopot, Grocka, Obrenovac) sa preko 150 učesnika uzrasta 5-14 godina.

Organizacija Slobodna zona Junior nastala je u okviru Fonda B92 i filmskog festivala angažovanog filma Solobodna zona. Ovaj program pokrenut je kao odgovor na potrebu za modernizacijom nastave pružanjem podrške institucionalnom dizanju svesti među mladima o pitanjima ljudskih prava. Cilj je da se kroz audio-vizuelne umetnosti i vannastavne aktivnosti srednjoškolcima i osnovcima pruži prilika da na kreativan način izraze svoje stavove. Edukativni program Slobodna zona Junior podeljen je na dva segmenta: Film kao dodatno nastavno sredstvo i Kamp angažovanog dokumentarnog filma za srednjoškolce. Kroz program Film kao dodatno nastavno sredstvo, u okviru predmeta građansko vaspitanje, Slobodna zona Junior nastoji da modernizuje nastavu i učini je interaktivnom. Program je namenjen nastavnicima u osnovnim i srednjim školama, a obuhvata izdavanje DVD kompilacije edukativnih angažovanih filmova, publikovanje priručnika sa predloženim radionicama koji prate filmove iz kompilacije, kao i organizovanje seminara za korišćenje filma u nastavi. U ovom programu od 2006. godine do danas učestvovala su 524 nastavnika iz 268 srednjih škola i 86 gradova širom Srbije. Tokom školske 2011/2012. 
Slobodna zona Junior izdala je prvi priručnik za osnovne škole uz prateću kompilaciju filmova i organizovala 27 radionica za nastavnike u kojima je učestvovalo 667 prosvetnih radnika iz 426 osnovnih škola iz 181 mesta širom Srbije.

Kamp angažovanog dokumentarnog filma Slobodna zona Junior koncipiran je kao radionica za srednjoškolce. Cilj radionice jeste da grupi izabranih srednjoškolaca pruži uvid u uzroke, posledice i domete društvenog aktivizma, u različite aspekte kreiranja društveno angažovanog filma, da ih ohrabri na interkulturalni dijalog, podstakne i podrži u razvijanju sopstvenih ideja. Kamp se sastoji iz dva dela. Tokom prvog (dvonedeljnog) dela kampa polaznici stiču veštine u pisanju scenarija, dramaturgiji, strukturi filma, montaži, kameri, ali i znanja o istorijatu i karakteristikama dokumentarnog filma, sa posebnim osvrtom na primere angažovanog filma. Polaznici imaju priliku i da se susretnu sa rediteljima i producentima angažovanih dokumentarnih filmova iz regiona. $U$ drugom (sedmodnevnom) delu kampa polaznici rade na oživljavanju svojih ideja filmskih scenarija. Uz predavanja o pičingu i vežbe prezentovanja svojih ideja filmskim profesionalcima, oni se pripremaju za završni deo kampa, a to je realizacija sopstvenih kratkih dokumentarnih filmova.

Evropske studije Za evropsku filmsku obrazovnu politiku i Medijska (ekranska) pismenost, filmsko obrazovanje u Evropi ukazuju na važnost medijskog, ali i posebno filmskog, obrazovanja i pismenosti kod dece i omladine. Naročito važno u ovim studijama je to što one prepoznaju i na prvom mestu ističu školske kurikulume kroz koje će se deca upoznavati sa slikama i ekranima koji ih okružuju. Kao dobri modeli uzimaju se francuski programi Škola u bioskopu, Škola filma i Filmski početnici i učenici. Srbija se zahvaljujući edukativnim programima Film kultura i Slobodna zona Junior približava evropskim trendovima, ali samo u vanškolskim aktivnostima. Za sada u našoj zemlji u sistemu formalnog školskog obrazovanja (predškolskog, osnovnoškolskog, srednjoškolskog itd.) ne postoji veza između kurikuluma i medijske pismenosti. Potreba za funkcionalnom povezanošću ekranske kulture, medijske pismenosti, audio-vizuelnog obrazovanja i školskih kurikuluma danas je sve izraženija jer su deca i omladina potpuno okruženi medijima i ekranima: kuda god da se kreću, oni su svuda oko njih, a da pritom ne znaju na koji način nastaju i šta znače slike koje im se 
na tim ekranima nude. Uspostavljanje novih obrazovnih programa u ovom smeru omogući će im da pokretne slike na ekranima svih vrsta razumeju pre svega kao sredstvo kreativnog izražavanja i komunikacije.

\section{Literatura:}

Bergala, Alain (2002) L'hypothèse cinéma: Petit traité de transmission du cinéma à l'école et ailleurs. Paris: Cahiers du cinéma

Christie, Ian (2012) "Introduction: In Search of Audiences?" in I. Christie (ed.) Audiences, Amsterdam: Amsterdam University Press, pp. 11-22.

Christie, Ian (2012) "What Do We Really Know About Film Audiences?" in I. Christie (ed.) Audiences, Amsterdam: Amsterdam University Press. pp. 225-234

Dragićević Šešić, Milena i Dragojević, Sanjin (2005) Menadžment umetnosti u turbulentnim okolnostima, Beograd: Clio

Đukić, Vesna (2010) „Obrazovna i kulturna politika: Dramske umetnosti u školama“, Zbornik Fakulteta dramskih umetnosti br.16, Beograd: Fakultet dramskih umetnosti, str. 195-209.

Eurodata TV Worldwide study (2013), na lokaciji: http://www.mediametrie.com/ eurodatatv/?univers=eurodatatv pristupljeno decembra 2015.

European Audiovisual Observatory, Yearbook 2012 (2013), na lokaciji: http://www.obs. coe.int/en/home pristupljeno decembra 2015.

Eurostst: Frequency of going to cinema, live performances, cultural sites or attending live sport events by sex and age (31.01.2014) na lokaciji: http://appsso.eurostat. ec.europa.eu/nui/show.do?dataset=yth_cult_010\&lang=en pristupljeno januara 2016.

Film Kultura na lokaciji: http://www.filmkultura.org/sr/ pristupljeno decembra 2015.

Grodal, Torben (2012) "Tapping into Our Tribal Heritage, The Lord of the Rings and Brain Evolution", in I. Christie (ed.) Audiences, Amsterdam: Amsterdam University Press. pp. 128-142

Jullier, Laurent and Leveratto, Jean-Marc (2012) "Cinephilia in the Digital Age", in I. Christie (ed.) Audiences, Amsterdam: Amsterdam University Press. pp. 143-154

Lardoux, Xavier (2014) For a European Film Education Policy, na lokaciji: http://www. kulturnibazar.si/scripts/download.php?file=/data/upload/For_a_European_ Film_Education_Policy_A_Report_by_Xavier_Lardoux.pdf pristupljeno decembra 2015.

Nussbaum, Martha (2010) Not for profit - Why democracy needs the humanities, Princeton, NJ: Princeton University Press

Manovich, Lev (1998) "Towards an Archaeology of the Computer Screen" in T. Elsaesser and K. Hoffmann (eds.) Cinema Futures: Cain, Abel or Cable? The Screen Arts in the Digital Age, Amsterdam: Amsterdam University Press. pp. 27-44 
McLuhan, Marshall (1964) Understanding Media: The Extensions of Man, London: McGraw Hill

Milovanović, Aleksandra (2014) „Umnožavanje ekrana u savremenoj kulturi i medijma: Od minijaturnih do kolosalnih, od statičnih do pokretnih ekrana", u M. Šešić, M Nikolić i Lj. Rogač (ur) Zbornik radova Kultura i održivi razvoj u doba krize, Beograd: FDU, str. 133-150.

Simons, Ian (2009) "Pockets in the Screenscape movies on the move", na lokaciji: http:// web.mit.edu/comm-forum/mit6/papers/Simons.pdf, pristupljeno marta 2014.

Simons, Ian (2011) "Between IPhone and Youtube: Movies on the Move", in Lovink, Geert \& Somers Miles, Rachel (eds), Video Vortex Reader II: Moving Images Beyond YouTube, Amsterdam: Institute of Network Cultures. pp. 95-107

Postman, Neil (1979) Teaching As a Conserving Activity, New York: Delacorte Press

Odin, Roger (2012) "Spectator, Film and the Mobile Phone", in I. Christie (ed.) Audiences, Amsterdam: Amsterdam University Press. pp. 155-16

Oever, Annie Van Den (2012) "The Aesthetics and Viewing Regimes of Cinema and Television", in I. Christie (ed.) Audiences, Amsterdam: Amsterdam University Press. pp. 113-127.

Reid, Mark (2013) Screening Literacy, Film Education in Europe, London: BFI

Slobodna Zona Junior, na lokaciji: http://www.freezonebelgrade.org/slobodna-zonajunior pristupljeno decembra 2015.

T. Troscianko, T. S. Meese, S. Hinde (2012) "Perception While Watching Movies: Effects of Physical Screen Size and Scene Type," i-Perception 3, no.7. pp. 414-425.

Verhoeff, Nanna (2012) Mobile Screens, The Visual Regime of Navigation, Amsterdam: Amsterdam University Press

Williams, Raymond. (1974) Television: Technology and Cultural Form, London: Collins 


\title{
Aleksandra Milovanović \\ University of Belgrade \\ Faculty of Dramatic Arts
}

\section{MEDIA LITERACY: (IN)COHERENCE OF SCREEN CULTURE AND SCHOOL CURRICULUM}

\begin{abstract}
Summary
Children and young people are surrounded by screens and everywhere they go they are around them: at home (television, computer, video game station, etc.), in school, in car, on the street, next to the highway, in public transportation (bus, train, etc.), in shopping malls, waiting rooms, sport arenas, etc., and in exceptional situation when there are no screens around them, they can always turn to the screen on their mobile phones and tablets, which are always next to them. Research of European experts for education in the study For a European Film Education Policy (2014) showed that children spend 900 hours a year in school compared to 1,200 hours in front of a screen (of any kind), while they don't know how the images on those screens are generated and what they mean. The aim of this paper is to examine the role, function and importance of the screens in contemporary screen culture and analyses whether in the formal school education in Serbia (pre-school, primary school, secondary school, etc.) there is a connection between curriculum and media literacy.
\end{abstract}

Key words: media, screens, education, media literacy 